\title{
Overhead line design considerations for conductor creep mitigation
}

DOI:

10.1049/iet-gtd.2015.1186

\section{Document Version}

Submitted manuscript

Link to publication record in Manchester Research Explorer

\section{Citation for published version (APA):}

Kopsidas, K., Boumecid, B., \& Cooper, I. P. (2016). Overhead line design considerations for conductor creep mitigation. IET Generation, Transmission and Distribution, 10(10), 2424 - 2432. https://doi.org/10.1049/ietgtd.2015.1186

\section{Published in:}

IET Generation, Transmission and Distribution

\section{Citing this paper}

Please note that where the full-text provided on Manchester Research Explorer is the Author Accepted Manuscript or Proof version this may differ from the final Published version. If citing, it is advised that you check and use the publisher's definitive version.

\section{General rights}

Copyright and moral rights for the publications made accessible in the Research Explorer are retained by the authors and/or other copyright owners and it is a condition of accessing publications that users recognise and abide by the legal requirements associated with these rights.

\section{Takedown policy}

If you believe that this document breaches copyright please refer to the University of Manchester's Takedown Procedures [http://man.ac.uk/04Y6Bo] or contact uml.scholarlycommunications@manchester.ac.uk providing relevant details, so we can investigate your claim.

\section{OPEN ACCESS}




\title{
Overhead Line Design Considerations for Conductor Creep Mitigation
}

\author{
Konstantinos Kopsidas $^{1 *}$, Boudjemaa Boumecid ${ }^{2}$, Ian P. Cooper ${ }^{3}$ \\ ${ }^{1}$ School of Electrical and Electronic Engineering, The University of Manchester, Manchester, \\ UK \\ ${ }^{2}$ Power Systems Department, Saudi Aramco, Abqaiq, Saudi Arabia \\ ${ }^{3}$ UK Power Networks, Crawley, UK \\ *k.kopsidas@manchester.ac.uk
}

\begin{abstract}
Utilities are continuously investigating methods to economically reinforce their overhead line (OHL) networks by reconductoring with larger conductors or with novel high-temperature low-sag (HTLS) conductor technologies. To further optimize the OHL design, conductor creep ageing is calculated and mitigated at installation, which economically improves an OHLs' performance. An already established methodology is used to investigate common and HTLS conductors ageing effect on sag and tension in order to highlight the benefits and risks that could result from existing creep mitigation methods particularly on HTLS conductors. The paper aims to identify the impact of important design factors, such as ice loading and emergency operation events and their frequency of occurrence, on creep mitigation as well as to highlight the creep variation of the same materials used particularly on different HTLS conductors. The analysis presented here indicates that pre-tensioning could be more beneficial on soft aluminium HTLS conductors while over-tensioning can result in extensive durations of conductor over-stressing on steel supported and gap type conductors. Furthermore, the conductor technology majorly affects the creep of steel core which cannot be considered always as zero. The accuracy of the methodology is also re-validated using recent experimental data from gap conductor.
\end{abstract}

\section{Introduction}

In an effort to increase the transfer capacity of overhead lines (OHL) with traditional aluminium conductor steel reinforced (ACSR), their replacement with all aluminium alloy conductors (AAAC) was first implemented. This has shown to increase the ampacity for the same conductor diameter and the strength-to-mass ratio resulting in higher installation tensions and ground clearances. However, the uniform distribution of mechanical load of AAACs increases the effect of aeolian vibrations compared to ACSRs which have better self-damping performance due to unequal force distribution between the steel and aluminium [1]. Vibration performance of non-uniform conductors further improves at operating temperatures above installation due to differential thermal expansions of steel and aluminium. This thermal expansion asymmetry of bimetallic/bi-material conductors leads to aluminium zero tensile force (i.e., becomes slack) at high operating temperatures. Conductor sag, then, is determined solely by the core. This property is currently utilized on novel high-temperature low-sag (HTLS) conductors to further optimize the power capacity of OHLs. 
The most commonly implemented HTLS technologies are: aluminium conductor steel supported (ACSS) with the soft/annealed aluminium providing the conduction and the steel core providing most of the tensile strength [2]; zirconium treated aluminium conductor invar reinforced (ZTACIR) whose steel core and aluminium are specially processed to reduce thermal expansion and maintain strength at high temperatures [3]; gap-type ACSR (GZTACSR) that allows to easily control the conductor's knee-point temperature (KPT) at installation [4]; aluminium conductor composite reinforced (ACCR) [5]; and aluminium conductor composite (non-conductive) core (ACCC) [6]. The last two technologies use lighter core material than steel to further improve strength-to-mass ratio (compared to AAACs) and improve the overall OHL performance.

The traditional AAACs and ACSRs have both core and aluminium components under tension for their complete range of operating temperatures [7]. HTLS conductors, on the other hand, have a force distribution between core and aluminium components that is affected considerably by the operating temperature as well as by the design technology resulting in different creep on the two components. This requires reconsidering the effectiveness of traditional mitigation methods implemented during the installation of the conductors to mitigate the expected conductor creep during its operational life $[8,9]$.

This paper examines the conductor creep ageing of the traditional AAACs and ACSRs and the most implemented HTLS conductor technologies in order to identify any complexities that should be considered during their installation. It, therefore, evaluates the effectiveness of pre-tensioning and over-tensioning based on critical conductor properties and high temperature operation on sag-ageing performance. This is important in order to evaluate a conductor's final ampacity (i.e. accounting for creep) and to identify conductors with improved creep performance, which is not usually considered in OHL evaluation studies $[10,11]$

The next two sections discuss the conductor creep and mitigation methods, and the methodology employed. Section 4 then examines the effectiveness of these methods on the creep mitigation due to every-day operating conditions. Section 5 investigates the impact of extreme weather and emergency operating conditions on creep and sag. Finally, the paper examines the accuracy of the methodology against experimental measurements on gap conductor and concludes with the complexities that may arise.

\section{Conductor creep \& methods for its mitigation}

Conductor creep is the permanent conductor elongation due to the tensile forces, which increases its sag. As resolution, safety buffers are required to maintain the ground clearances over conductor's lifetime, or a creep mitigation technique is implemented at installation, to avoid the increased cost incurring with the safety buffers. For both resolutions, there are methods, of various complexity and accuracy, which predict the creep of common and HTLS conductors [8, 12-14]. Incorrect prediction could result in understressing the conductor limiting OHL ampacity or in over-stressing it with a risk to damage the OHL 
integrity. Independently of the methodology employed it is important to consider all the expected conditions of the OHL system and conductor's structure.

\subsection{Types of Conductor Creep}

There are two types of creep based on how it is produced: geometrical settlement and metallurgical deformation.

Geometrical settlement results from abnormal high conductor tensions at severe weather. As strands settle closer to each other plastic deformation occurs at the crossover contact point of strands from different layers [15]. This occurs on soft metals (i.e. aluminium) and affects the whole conductor [16]. Although this type of creep is not a function of time, this process occurs within one hour of conductor exposure to high tensions. Longer durations of high tensions do not produce any additional geometrical settlement; however metallurgical deformation is developed.

Metallurgical deformation results from material exposure to mechanical and thermal stress over time $[15,17]$. Two types of metallurgical creep are formed: normal temperature (long-term) creep and elevated temperature creep. The latter is an accelerated deformation occurring only at emergency elevated temperature operating conditions, which happens for a few hours per year, and it affects aluminium alloys that are not specially treated to resist high-temperature annealing [18].

\subsection{Conductor Creep Mitigation Methods}

Pre-tensioning and over-tensioning are the creep mitigation techniques that could be applied (individually or in combination) during the conductor installation to maximize an OHL's thermal rating [19].

Pre-tensioning is the temporary tensioning of the conductor at a pre-determined tension, temperature and duration before it is clamped at the designed installation conditions [16]. The technique is based on the principle that the creep is an exponential function of time and therefore a small initial pre-tension (PT) duration can remove a considerable amount of creep. The longer the duration and the higher the tension at pre-tensioning, the more effective the method is. However, this requires longer conductor installation times, which increase costs.

Over-tensioning involves increasing installation tension above the required design value to compensate for the creep [20]. This over-tension (OT) usually refers to an equivalent negative temperature-shift which results in a thermal contraction equal to the creep elongation, mitigating thus the resultant conductor creep (i.e., both metallurgical and geometrical settlement due to extreme weather loading). Unlike PT, this technique is quite effective as it is faster and easier to apply. However, when it is implemented the composite conductor creep effect is considered [21] neglecting the creep difference in conductor (aluminium and core) components of non-homogeneous types. This can introduce errors in final 
sag calculations and the required OT, particularly on HTLS conductors. An additional source of error is introduced by the extra creep generated by the OT itself as in many occasions it is neglected [21]. Concerns about over-tensioning also arise due to initial higher tensions that could affect conductor vibration performance and/or cause OHL fatigue under severe ice loading during the first years after installation [22].

When implementing both methods the calculations should consider OHL system properties along with heavy weather, everyday conditions and operational data. All those define the expected ageing and, therefore, the amount of PT and/or OT that could safely be applied without exceeding any design constraints. It is also important to consider the durations that the conductor is expected to experience increased tensions and operate at emergency elevated temperatures. These considerations are addressed within the methodology presented next.

\section{Methodology}

\subsection{Conductor Creep Calculations}

To calculate the conductor ampacity on an OHL system, the amount of creep (due to long-term, expected emergency thermal operation and ice loading conditions) should be computed. Fig. 1 illustrates the flowchart of the calculations performed to predict the ageing for an OHL system and its conductor sag and thermal rating when creep mitigation is applied.

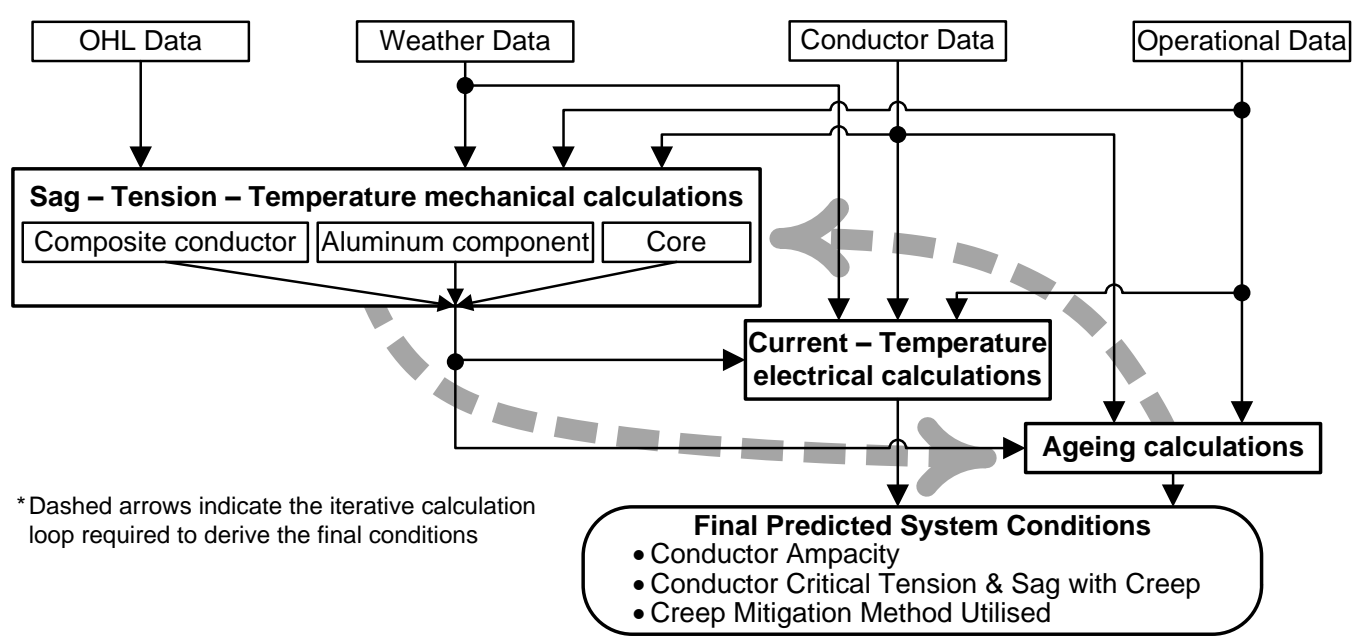

Fig. 1. Flow chart of the computations for system performance

As shown in Fig. 1 the Sag-Tension-Temperature mechanical calculations are performed at the start and then the output feeds into the Current-Temperature electrical and ageing calculations. An iterative loop is implemented for the creep ageing calculations. This is important as the creep developed in the aluminium is different from that developed in the core $[13,23,24]$. Consequently, creep affects the force distribution of the conductor components and the temperature at which compressive forces are developed. This, in turn, affects the additional creep produced on each conductor component. Therefore, the SagTension-Temperature mechanical calculations are performed for the composite conductor, its aluminium 
and its core. For all-aluminium conductors the core is considered as part of the aluminium component. Once the creep for conductor designed duration is calculated the KP is calculated then from the mechanical calculations. The details of each individual computational step of these sag-tension-ageingrating calculations of overhead lines (STARcol) are presented elsewhere [13, 23]. These calculations are mainly based on conductor material and geometrical properties as well as methodological steps that are described in [14] and [15] while considering the individual creep equations (1) and (2) for aluminium and steel, accordingly [14]. $t$ is the time (in years) and $\sigma$ the conductor stress (in MPa). This allows for the calculations described in $[13,23]$ to account for both aluminium and steel creep when conductors are designed using these materials; when composite materials are used their experimental curves are also implemented.

$$
\begin{aligned}
& \text { creep }_{A l}=7.8 \times 10^{-6} \times t^{0.3} \times \sigma_{A l}^{1.3} \times e^{0.03(T-20)} \\
& \text { creep }_{S t}=0.003 \times t^{0.13} \times\left(\frac{\sigma_{S t}}{\sigma_{S t}^{R T S}}\right)^{4.7} \times e^{0.02(T-20)}
\end{aligned}
$$

\subsection{Description of the studied OHL System}

The analyses are implemented on a standard $275 \mathrm{kV}$ lattice tower system with $366 \mathrm{~m}$ span and the design details shown in Table 1. The conductor properties and their reference installation conditions considered in the study are summarized in Table 2. Compressive forces (CF) are included where appropriate. When creep negation is implemented the analysis considers the final tension (i.e., the tension after the conductor design life has been elapsed) at everyday temperature to be equal to $20 \%$ of the conductor's rated breaking strength (RBS) (Table 2).

In order to enable the comparison of conductors' creep performance, which is the focus of this study, various safety factors and structure reinforcements are assumed throughout the analyses to allow the implementation of any required conductor OT.

Table 1 OHL Structure Properties

\begin{tabular}{l|c|c}
\hline \multirow{2}{*}{ Tower strength $[\mathrm{kgf}]$} & Tension & 7983.36 \\
\cline { 2 - 3 } & Weight & 7767.79 \\
\cline { 2 - 3 } & Transverse & 2891.65 \\
\hline Insulator Weight $(\mathrm{kg})$ & \multicolumn{2}{|c}{215} \\
\hline Number of Conductor per Bundle & \multicolumn{2}{|c}{2} \\
\hline Emergency Elevated Conductor Temp. $\left({ }^{\circ} \mathrm{C}\right)$ & 90 \\
\hline Maximum Conductor Temp. $\left({ }^{\circ} \mathrm{C}\right)$ & 70 \\
\hline Minimum Conductor Tension Temp. $\left({ }^{\circ} \mathrm{C}\right)$ & -5.6 \\
\hline Ice Thickness $(\mathrm{mm})$ & 12.5 \\
\hline Ice Density $\left(\mathrm{kg} / \mathrm{m}^{3}\right)$ & 913 \\
\hline Wind Pressure $\left(\mathrm{kgf} / \mathrm{m}^{2}\right)$ & 38.75 \\
\hline
\end{tabular}


Table 2 Conductor Properties and Reference Installation Conditions

\begin{tabular}{lccccc}
\hline Conductor Code Name & $\begin{array}{c}\text { ACSR } \\
\text { Lynx }\end{array}$ & $\begin{array}{c}\text { AAAC } \\
\text { Upas }\end{array}$ & $\begin{array}{c}\text { ACSS } \\
\text { Drake }\end{array}$ & $\begin{array}{c}\text { ACCR } \\
\text { Drake }\end{array}$ & $\begin{array}{c}\text { GZTACSR } \\
\text { Matthew }\end{array}$ \\
\hline Stranding Pattern & $30 / 7$ & $37 / 0$ & $26 / 7$ & $26 / 19$ & $40 / 7$ \\
Cond. Diameter $(\mathrm{mm})$ & 19.53 & 24.71 & 28.13 & 28.63 & 31.48 \\
Cond. Area $\left(\mathrm{mm}^{2}\right)$ & 226.20 & 362.11 & 468.61 & 483.74 & 685.62 \\
Mass $(\mathrm{kg} / \mathrm{m})$ & 0.8420 & 0.9975 & 1.6284 & 1.3764 & 2.2160 \\
RBS $(\mathrm{kgf})$ & 8247.8 & 10892.9 & 11543.7 & 15363.5 & 18104.4 \\
$\mathrm{CF}$ method & as in [13] & N/A & as in [13] & as in [13] & as in $[13]$ \\
Installation Temp. $\left({ }^{\circ} \mathrm{C}\right)$ & 5 & 5 & 5 & 5 & 10 \\
Installation Tension & 5 & $20 \%$ RBS (neglecting creep) & \\
Everyday Temp. $\left({ }^{\circ} \mathrm{C}\right)$ & 5 & 5 & 5 & 5 & 10 \\
Design life $(\mathrm{y})$ & 30 & 30 & 30 & 30 & 30 \\
\hline
\end{tabular}

For increased calculation accuracy the creep developed during the stringing process is considered by implementing a 1-hour 10\% RBS "running-out" simulation step. This creep, thus, is removed prior to the conductor clamping as it occurs in actual installations.

This system is used along with the methodology presented earlier to evaluate the creep effect without (Section 4) and with extreme events (Section 5) using two case studies, the details of which are presented along with the results in the corresponding sections. It should be noted that the conductor technologies are compared based on their creep performance and therefore the "effectiveness" to mitigate creep effects is evaluated. For comparability reasons, thus, HTLS conductors are not examined at temperatures above $90^{\circ} \mathrm{C}$ even though they can operate at $150-200^{\circ} \mathrm{C}$ [25]; this comparative analysis of HTLS conductors is studied in $[25,26]$.

\section{Conductor Long-term Creep Mitigation}

The efficiency of different creep mitigation techniques on the negation of metallurgical deformation is evaluated first considering zero weather loading and no emergency operating conditions.

\subsection{Duration and tension effect on conductor pre-tensioning}

Pre-tensioning at installation is investigated using the conductors in Table 2 apart from GZTACSR since its installation is based on core tensioning and therefore it is not practical to pre-tension this conductor type.

Fig. $2 a$ shows the creep values for up to 120 hours when five different PTs are applied on common conductors (Lynx and Upas) in percentage to the final long-term creep. The most time-effective creep mitigation on both conductors is achieved during the first two hours. Additionally, the implemented tension affected the creep mitigation. As shown with Fig. $2 a$, for every 5\% RBS reduction in PT, an increase of PT duration by three to four times is required to achieve the same result. For Lynx, for example, a 6-hour 35\% RBS PT removes almost a third of the total expected creep. This is removed within a 2-hour $40 \%$ RBS or a 18-hour 30\% RBS PT respectively. Equation (3) is a practical approximation of the creep that can be removed from the AAACs and ACSRs for realistic durations of 2-72 hours of pre-tensioning. 
Equation (3) is derived mainly from the results illustrated in Fig. 2 in conjunction with similar results produced (using the same method) for other AAAC and ACSR [27] standard sizes but not presented here.

$$
\text { Creep }- \text { mit }_{\text {PreTens }}(\%)=1.15 \times R B S(\%)-\frac{20 \%}{\sqrt{t_{(\text {hours })}}}
$$

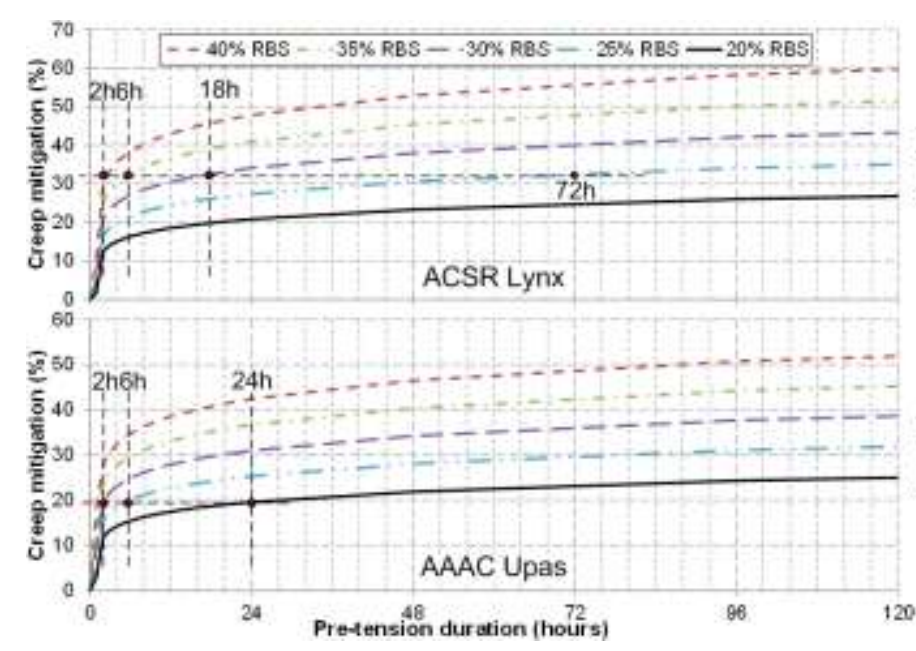

$a$

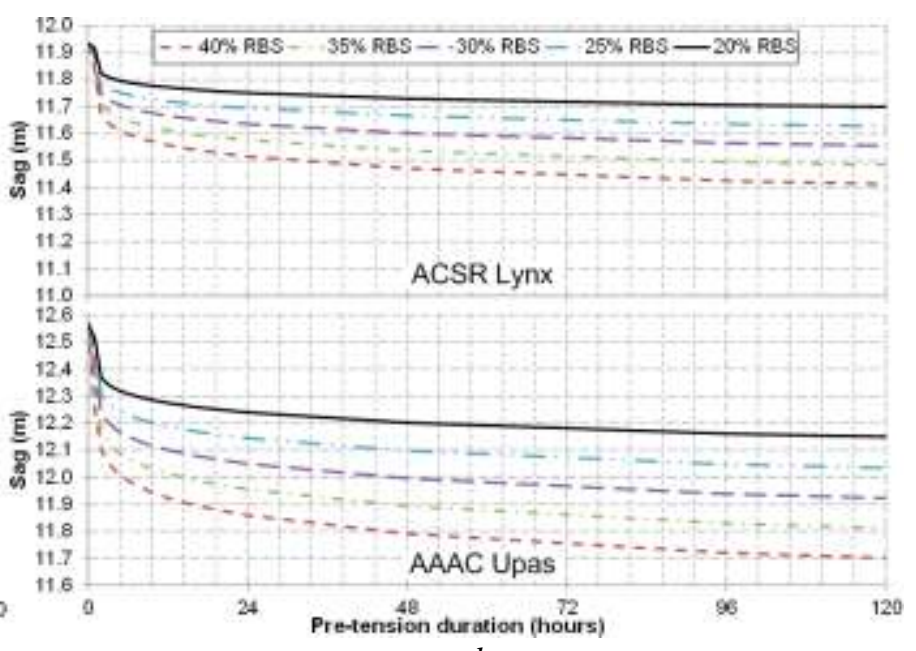

$b$

Fig. 2. (a) Creep mitigation achieved with different PTs applied on common conductors and (b) their corresponding final sag values at $70^{\circ} \mathrm{C}$ on the studied $\mathrm{OHL}$ system.

Fig. $2 b$ shows the corresponding sag values at $70^{\circ} \mathrm{C}$ for the different PT scenarios of Lynx and Upas. On the L3 system a $30 \mathrm{~cm}$ sag mitigation can be achieved on Lynx with a 12-hour 35\% RBS PT when the total creep effect on sag is $80 \mathrm{~cm}$. Upas' corresponding reduction in sag is $60 \mathrm{~cm}$ (when creep negation requires $1.7 \mathrm{~m}$ sag reduction).

Pre-tensioning, therefore, is ineffective for creep negation of common conductors as it achieves $45 \%$ maximum creep mitigation under realistic (up to $24 \mathrm{~h}$ ) durations.

It should also be noted that the creep mitigation percentage is equivalent to the mitigation of creep effect on sag. Therefore presenting the sag values, from this point forward, is sufficient to show the effectiveness of each mitigation method.

By examining the PT effect on ACSS and ACCR sag due to creep mitigation a very different pattern is seen (Fig. 3). In particular, creep negation on the ACSS is achieved by implementing a 1-hour $26.1 \%$ RBS PT with a resulted $13.47 \mathrm{~m}$ of sag, while any increase in duration has a negligible effect (Fig. $3 a$ ). This is due to the shift of conductor tensile stresses to the core once aluminium creep is formed. Thus, pretensioning is simpler to apply on annealed aluminium conductors since only 1 hour is needed. By implementing increased PTs more geometrical settlement is removed (which could be considered when the effect of ice loading on creep is negated). 


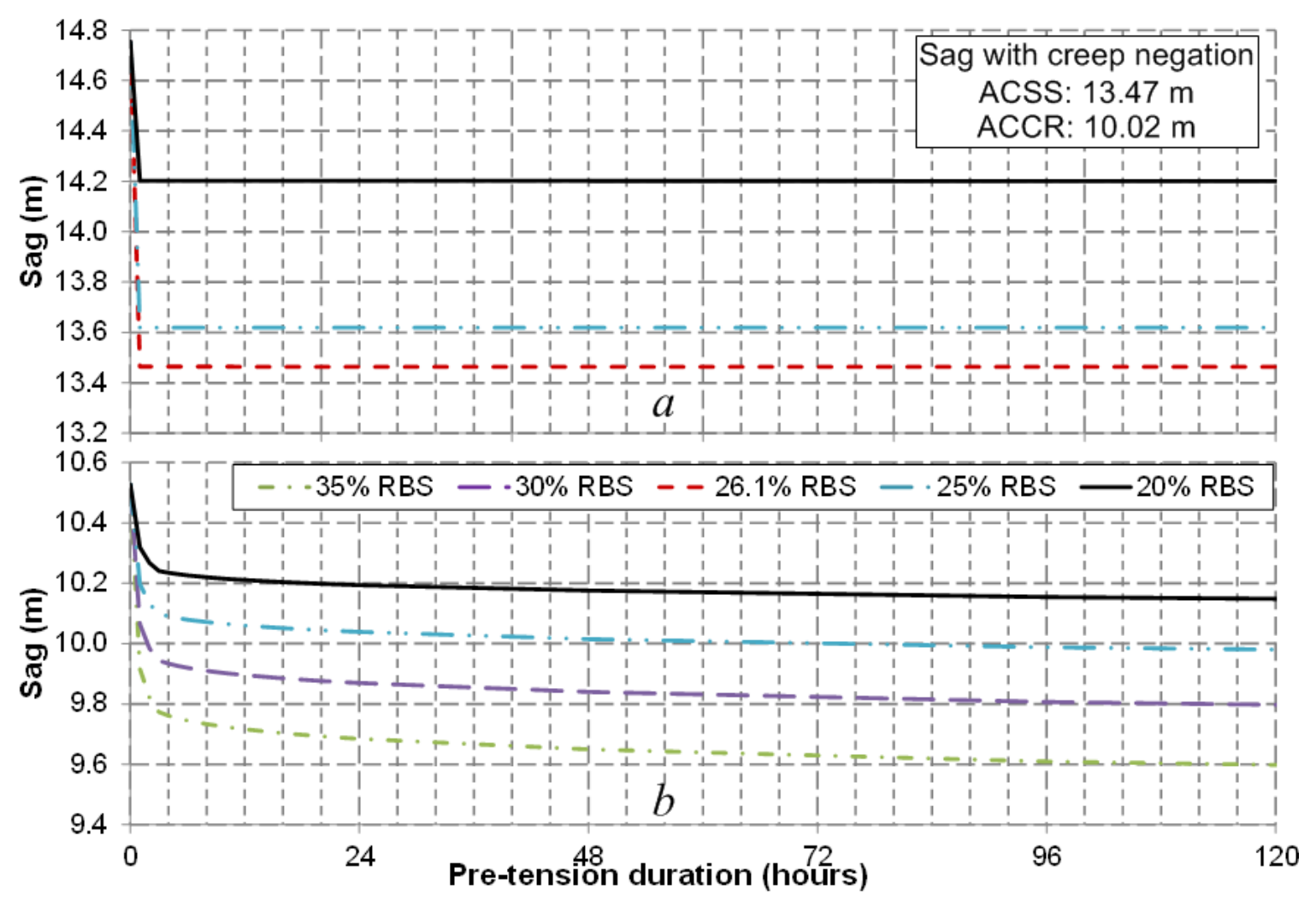

Fig. 3. Final sag of (a) ACSS Drake and (b) ACCR Drake, HTLS conductors for different PT scenarios.

Pre-tensioning ACCR Drake has similar effect to the common conductors with metallurgical deformation generated along with geometrical settlement since both aluminium and core parts contribute to conductor strength, as opposed to the ACSS. However, ACCR Drake also produces less metallurgical deformation compared to Lynx and Upas due to its stronger core and its lower aluminium-to-core crosssectional area ratio. Consequently a 2 -hour $30 \%$ RBS PT can negate its creep effect (to a final sag value of $10.02 \mathrm{~m}$ ) on the studied system (Fig. $3 b$ ).

The pre-tensioning behaviour of the ACSR, ACCR, ACSS and ACCR indicates that conductors with annealed aluminium can greatly benefit from pre-tensioning since geometrical settlement can be removed prior to final clamping; this pre-tensioning also reduces more effectively the conductors' KPT. However, additional geometrical settlement due to ice loading is usually expected which requires increased PTs that may not be practical to implement. In such cases over-tensioning or a combination of both creep mitigation methods would be more preferable solution.

\subsection{Everyday conditions and tension effect on over-tensioning}

Over-tensioning the conductor is fast and dependent on the conditions at the moment the conductor is clamped; however it is equally important to consider the long-term everyday conditions, i.e. every-day operating temperature (EDOT), the conductor is expected to experience. Fig. $4 a$ illustrates the sag of common conductors at $70^{\circ} \mathrm{C}$ for OTs up to $16 \%$ RBS increase in installation tension with different EDOTs 
and Fig. $4 b$ shows the calculated increase in creep values normalized at installation conditions, i.e. for creep expected at $5{ }^{\circ} \mathrm{C}, 20 \%$ RBS. The analysis is based on conductor properties of Table 2 with EDOT varying from $5^{\circ} \mathrm{C}$ to $25^{\circ} \mathrm{C}$ to capture the effect of increased average electrical loadings implemented by operators through post-installation changes in design exceedances.

At $5^{\circ} \mathrm{C}$ EDOT the ACSR requires approximately 3.2\% RBS (i.e. $28.6^{\circ} \mathrm{C}$ temperature shift) while the AAAC requires a $10.4 \% \operatorname{RBS}\left(52.2^{\circ} \mathrm{C}\right)$ OT to negate the creep. At $25^{\circ} \mathrm{C}$ EDOT the OTs needed are reduced to $2.8 \% \operatorname{RBS}\left(25.3^{\circ} \mathrm{C}\right)$ and $8.1 \% \operatorname{RBS}\left(43.5^{\circ} \mathrm{C}\right)$, respectively (Fig. $\left.4 a\right)$. Consequently, the increase in Lynx and Upas EDOT reduces the expected creep, increasing therefore conductor-to-ground clearances.

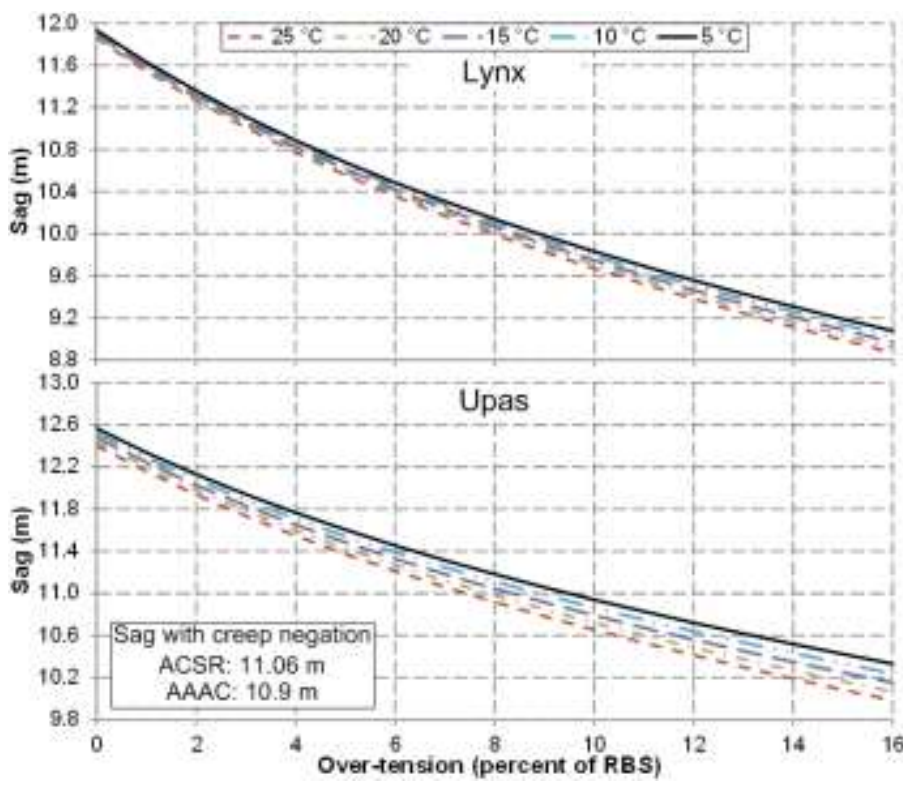

$a$

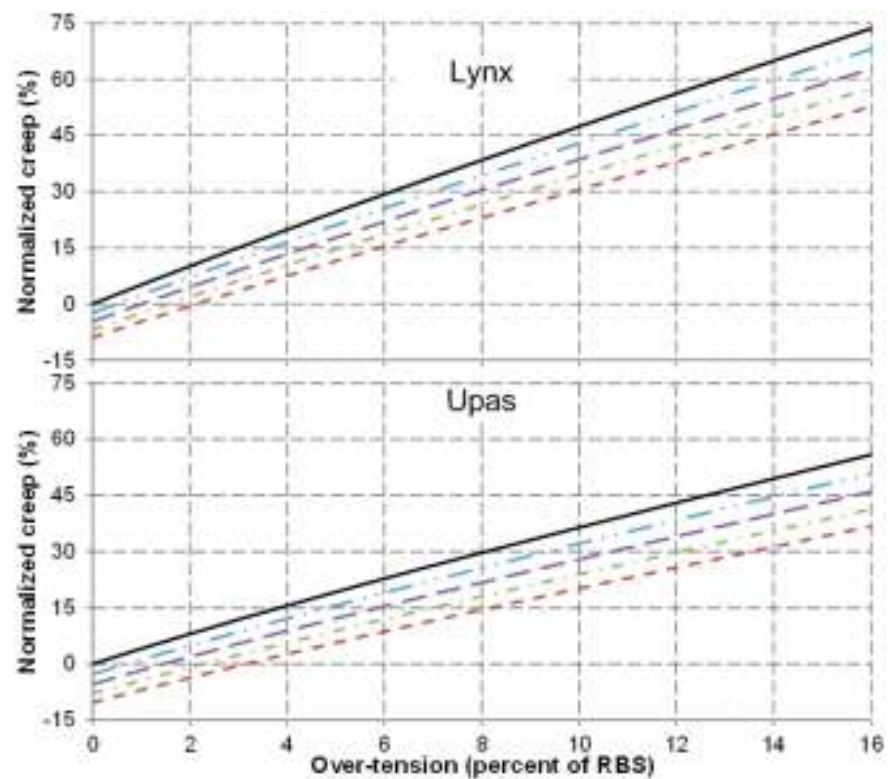

$b$

Fig. 4. Effect of different EDOT and OT conditions on (a) sag and (b) creep for common conductors

The applied OTs in Fig. 4 mitigate both the creep due to the installation at 20\% RBS and the creep developed from the OT effect. This analysis results thus in larger temperature shifts for creep negation compared to those recommended in [21]. In particular for every $2 \%$ increase in OT a $10 \%$ increase in Lynx's creep and 7.5\% in Upas's creep is apparent (Fig 4b). However, a reduction of 2.5\% in creep is observed for every $5^{\circ} \mathrm{C}$ increase in EDOT when no OT is applied. This doubles to $5 \%$ for a $12 \%$ RBS OT. Consequently both EDOT and OT greatly affect the expected creep with the worse installation scenario being at lower EDOT values.

Similar analyses for HTLS conductors are performed considering increased (up to $40^{\circ} \mathrm{C}$ ) EDOTs as higher thermal loadings, compared to those of common conductors, are expected. In Fig. 5 the final sags at $70^{\circ} \mathrm{C}$ of the investigated HTLS conductors are shown for comparability with the common conductors. This does not constrain the analysis of creep performance since all HTLS conductors examined here have their 
KPTs and compressive forces fully developed at much lower temperatures. Thus, sag values above $70^{\circ} \mathrm{C}$ are governed by core properties and do not affect the creep of HTLS conductors.

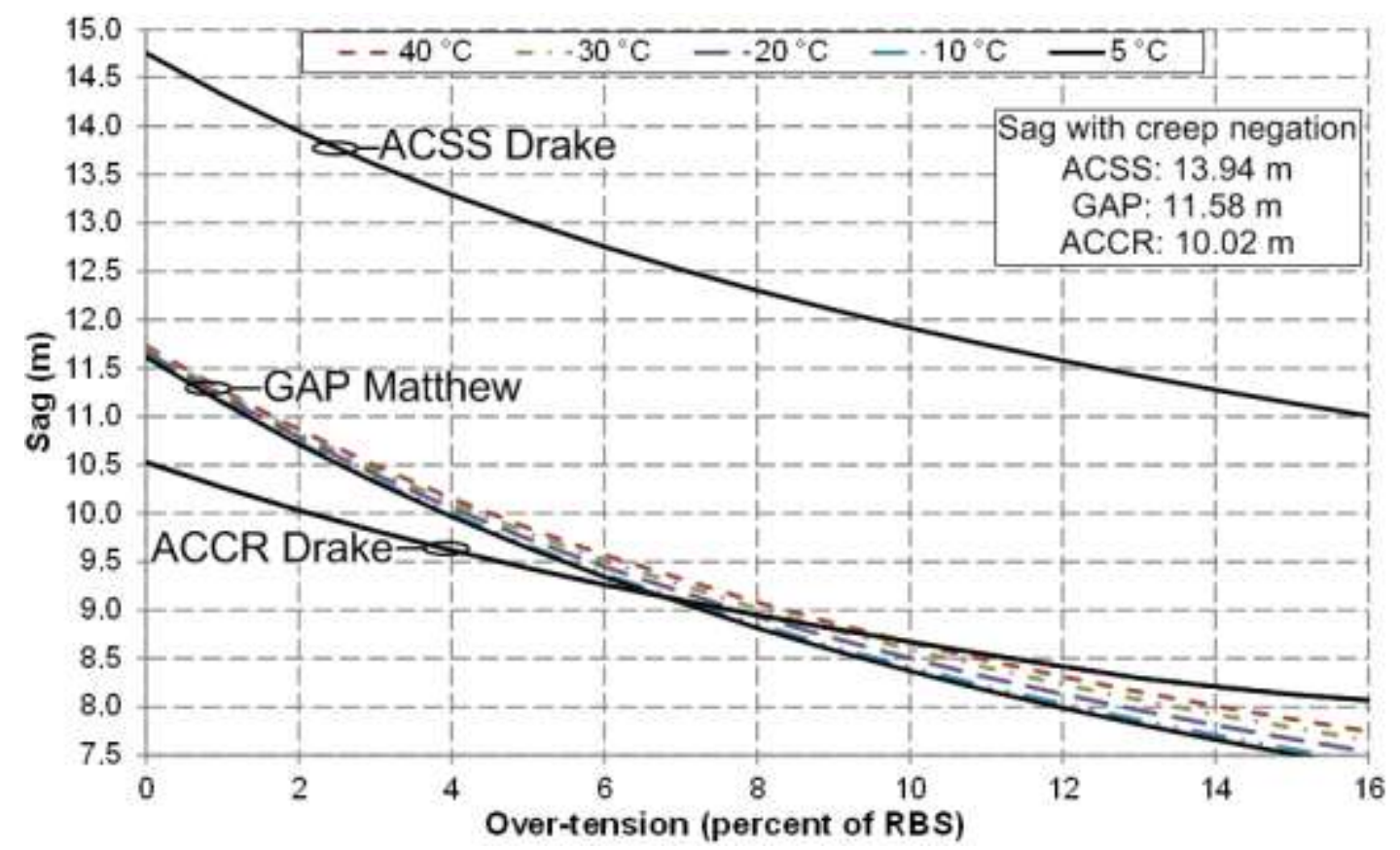

Fig. 5. Effect of EDOT and OT conditions on $70^{\circ} \mathrm{C}$ sag for ACSS Drake, ACCR Drake and Gap Matthew HTLS conductors

Changes on EDOTs do not affect the core creep of the ACSS and ACCR resulting in identical sag values at above KPT operation (Fig. 5); however Matthew develops up to a $32 \mathrm{~cm}$ increase in sag at $40^{\circ} \mathrm{C}$ EDOT (with 12\% OT). Although both ACSS and Gap have steel core, the lower KPT of Gap, compared to ACSS, and the different installation method results in higher stresses on the Gap core (above 20\%RBS) as opposed to ACSS core (below 12\%RBS) and any increase in Gap conductor EDOT increases its core's creep. ACSS and ACCR conductors KPTs are above the EDOT and therefore any future increase in thermal loadings will not affect their sag. For Gap, the sag above KPT is expected to increase when future loadings increase due to the higher long-term compressive forces on the core and higher long-term core temperatures as well. Therefore, the larger the aluminium cross-sectional area and the EDOT the more the core stress and creep, due to aluminium "dead weight" and compressive forces. It should be noted that $40^{\circ} \mathrm{C}$ EDOT is realistic when UK average temperature for $2009-2014$ period was approximately $9{ }^{\circ} \mathrm{C}$ and considering $20^{\circ} \mathrm{C}$ to $30^{\circ} \mathrm{C}$ of additional average electrical loading [28].

For the creep negation of the HTLS conductors lower OTs are required compared to common conductors (see Figs. 4 and 5). In particular a 2\% RBS OT on the ACSS and ACCR is needed (i.e. $28.85^{\circ} \mathrm{C}$ and $17^{\circ} \mathrm{C}$ temperature shifts respectively). Matthew's OT varies from $0.24 \%$ RBS to $0.46 \%$ RBS depending on the EDOT considered, which corresponds to $8^{\circ} \mathrm{C}-14^{\circ} \mathrm{C}$ core temperature shift. 
It is also important to note that the ACSS Drake's creep negation sag value with pre-tensioning (Fig. $3 a$ ) is much lower than the one with over-tensioning (Fig. 5). This is the result of pre-tensioning removing the aluminium creep prior to clamping which reduces its KPT after installation. Thus the $20 \%$ RBS installation tension after pre-tensioning is mainly applied on steel $(86 \%)$ while the installation with overtensioning at $22 \%$ RBS is distributed on both aluminium (60\%) and steel (40\%). Consequently, after elapsing of the 30 years of conductor design life the final tensions with both mitigation methods are $20 \%$ RBS at everyday temperature, however the core is tensioned more with pre-tensioning resulting in lower sags above KPT (and therefore at $70^{\circ} \mathrm{C}$ ).

\section{Impact of Extreme Events on Conductor Creep}

Every OHL is designed based on predictions of long-term operating conditions as well as extreme weather and emergency loading events. These extreme events affect conductor creep and therefore OHL's electro-mechanical performance. Consequently, this section aims to identify conductor creep (and therefore its mitigation) under real-life conditions of combined extreme events in a sequential manner during its design life.

\subsection{Conductor Performance under Ice Loading Conditions}

Most conductor creep analyses consider only the geometrical settlement due to ice loading that occurs during the first hour of installation. In reality, ice loading events occur randomly during the conductor life and occasionally ice is attached on the conductor for longer periods. Thus, sometimes ice loading could produce more creep than the expected geometrical settlement. In order to identify the worse design case, that needs to be considered in the design, five ice loading scenarios are modelled (Table 3) with various timings for first event occurrence and frequencies of events. For simplicity a constant amount of ice loading is considered (Table 1), therefore the impact of ice thickness and density is not captured. The multiple events are evenly distributed among the remaining period of conductors' design life. The base scenario considers no-ice and the OTs calculated in Section 4 (i.e., 10.4\% for Upas, 3.2\% for Lynx, 2\% for both Drakes, and $0.24 \%$ for Gap).

The creep performance of bimetallic conductors is investigated for the conductor and core, since the conductor creep affects the sag performance below the KPT (at ice loading), while the core creep affects the performance above the KPT.

Table 3 Ice Loading Scenario Data

\begin{tabular}{cccccc}
\hline Scenarios & Sc-1 & Sc-2 & Sc-3 & Sc-4 & Sc-5 \\
\hline Time of $1^{\text {st }}$ Occurrence (y) & 1 & 1 & 15 & 15 & 30 \\
Frequency of events & 1 & 6 & 1 & 3 & 1 \\
Total Duration (h) & & & 50 & & \\
\hline
\end{tabular}


Table 4 Creep Results (microstrains) for ICE Loading Scenarios

\begin{tabular}{lccccccccc}
\hline Name & \multicolumn{2}{c}{ Lynx } & \multicolumn{2}{c}{ Upas } & \multicolumn{2}{c}{ ACSS-Drake } & \multicolumn{2}{c}{ ACCR-Drake } & \multicolumn{2}{c}{ Matthew } \\
& Cond. Core & Cond. & Cond. & Core & Cond. & Core & Cond. Core \\
\hline Base & 518 & 3 & 1200 & 534 & 1 & 620 & 0 & 28 & 88 \\
Sc-1 & 535 & 11 & 1227 & 1076 & 15 & 812 & 0 & 93 & 92 \\
Sc-2 & 535 & 12 & 1228 & 1075 & 14 & 817 & 0 & 93 & 91 \\
Sc-3 & 573 & 14 & 1328 & 1075 & 14 & 820 & 0 & 95 & 92 \\
Sc-4 & 572 & 13 & 1328 & 1075 & 14 & 821 & 0 & 94 & 91 \\
Sc-5 & 593 & 14 & 1374 & 1074 & 13 & 873 & 0 & 95 & 88 \\
\hline
\end{tabular}

The calculated creep values, in Table 4, suggest that the frequency of events does not affect the creep for the specific OHLs. On the contrary, the timing of the first ice loading event does affect the final creep values for Lynx, Upas and ACCR Drake conductors. The worse creep is produced when the ice loading occurs at the end of the conductor's design life with the maximum metallurgical deformation and a large proportion of geometrical settlement. When the ice event occurs at the first winter (after conductor installation) the geometrical settlement is maximum; however, the metallurgical deformation after the event is reduced considerably resulting in lower overall creep.

Matthew's and ACSS Drake's creep performances are immune to the timing of the first ice loading event. However, their sag increases considerably due to ice loading, which indicates that a significant portion of aluminium creep is geometrical settlement while their metallurgical deformation is small. This considerably affects sag at low temperatures when compared to the sag at maximum thermal rating. This scenario could affect OHL designs with severe ice loading.

From Table 4 it can also be observed that both ACSS and Gap conductors' steel cores creep as expected from (2), however the stress on the cores are different (due to the different technology and installation method) and therefore, ACSS develops much smaller core creep (but not zero) compared to Gap.

In order to identify the effect of ice loading duration, Sc-1 is investigated with ice loading for up to 400 hours. Fig. 6 shows the sag values at thermal $\left(70^{\circ} \mathrm{C}\right)$ and ice $\left(-5.6^{\circ} \mathrm{C}\right)$ loading conditions in per-unit based on the base scenario values. Therefore, any increase in sag (from 1pu) is only due to additional creep from ice loading. 


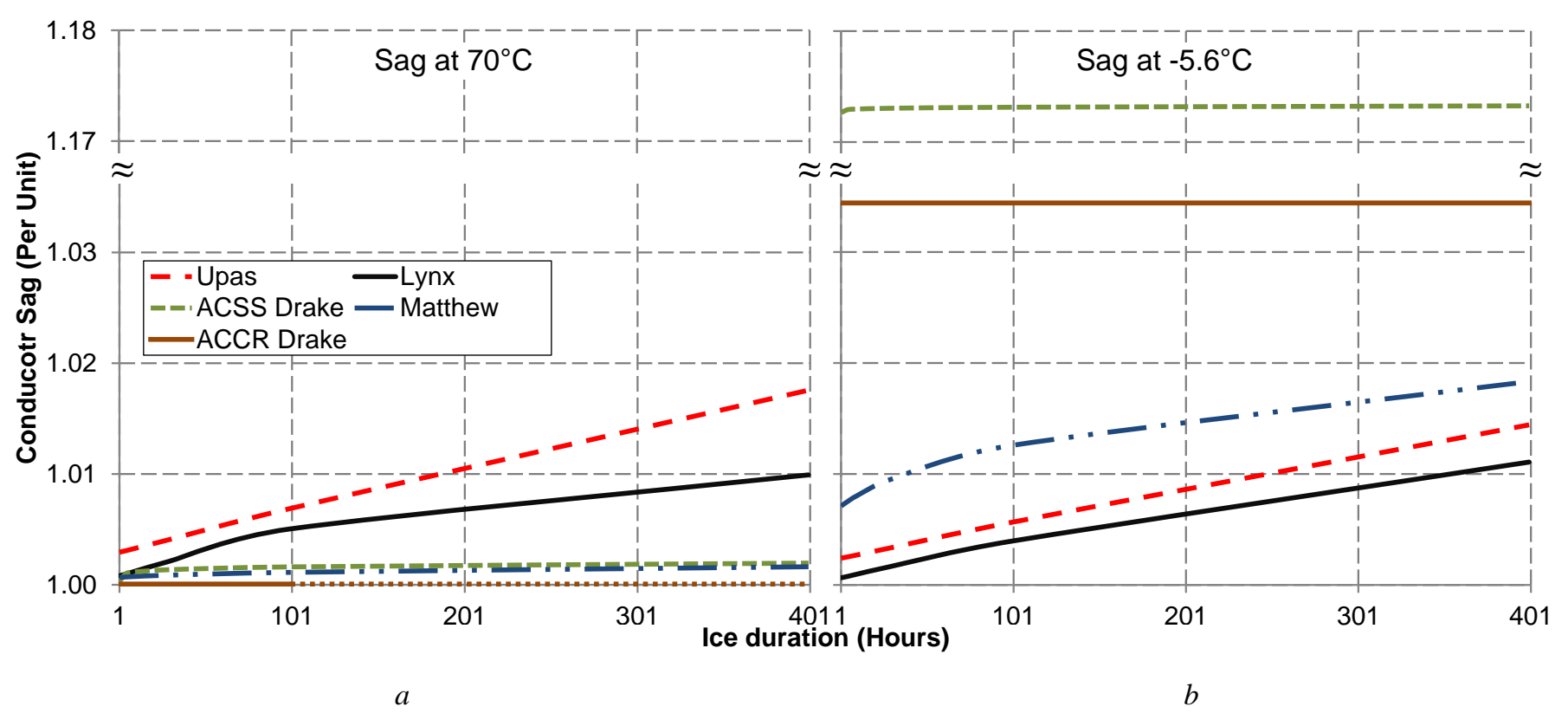

Fig. 6. Sag at (a) $70^{\circ} \mathrm{C}$ and at (b) $-5.6^{\circ} \mathrm{C}$ critical operating conditions for various ice loading durations.

The effect of ice duration on conductor sag differs between the common and HTLS conductors. Lynx and Upas are affected at both design temperatures in a similar manner (Fig. 6). The 400 hours additional ice loading increased the sag by $10 \mathrm{~cm}$ and $22 \mathrm{~cm}$ on Lynx and Upas respectively, at both $70^{\circ} \mathrm{C}$ and $-5.6^{\circ} \mathrm{C}$. HTLS conductors' sag performance, as expected, remained virtually unaffected by the ice loading at above KPTs. However, their sag at $-5.6^{\circ} \mathrm{C}$ is very different and will further differentiate at increased ice loadings; ACCR Drake and ACSS Drake sag performance is most affected by the ice loading with corresponding increase in sag by $34 \mathrm{~cm}(3.4 \%)$ and $2.37 \mathrm{~m} \mathrm{(17 \% )} \mathrm{across} \mathrm{all} \mathrm{durations} \mathrm{affecting}$ severely the OHL design, while Matthew's sag, increases by $21 \mathrm{~cm}(1.8 \%)$ after 400 hours of ice loading (Fig. 6b). Both ACSS and ACCR are not affected by the ice duration while Gap conductor is. This is due to the very little metallurgical deformation of Matthew's aluminium at everyday conditions since it is not under tension. This irregularity of creep performance at different operating conditions between the different examined conductor technologies indicates that using only over-tensioning to mitigate the creep could result in initial conductor over-stressing at everyday conditions for extensive durations until the first ice loading event occurs. This over-stressing is shown in Fig. 7 for initial OTs required to negate the creep produced by both long-term and the ice loading of Sc-3 (i.e., 10.66\% for Upas, 3.5\% for Lynx, $2.6 \%$ for ACSS Drake, $6.98 \%$ for ACCR Drake and $0.36 \%$ for Gap). 


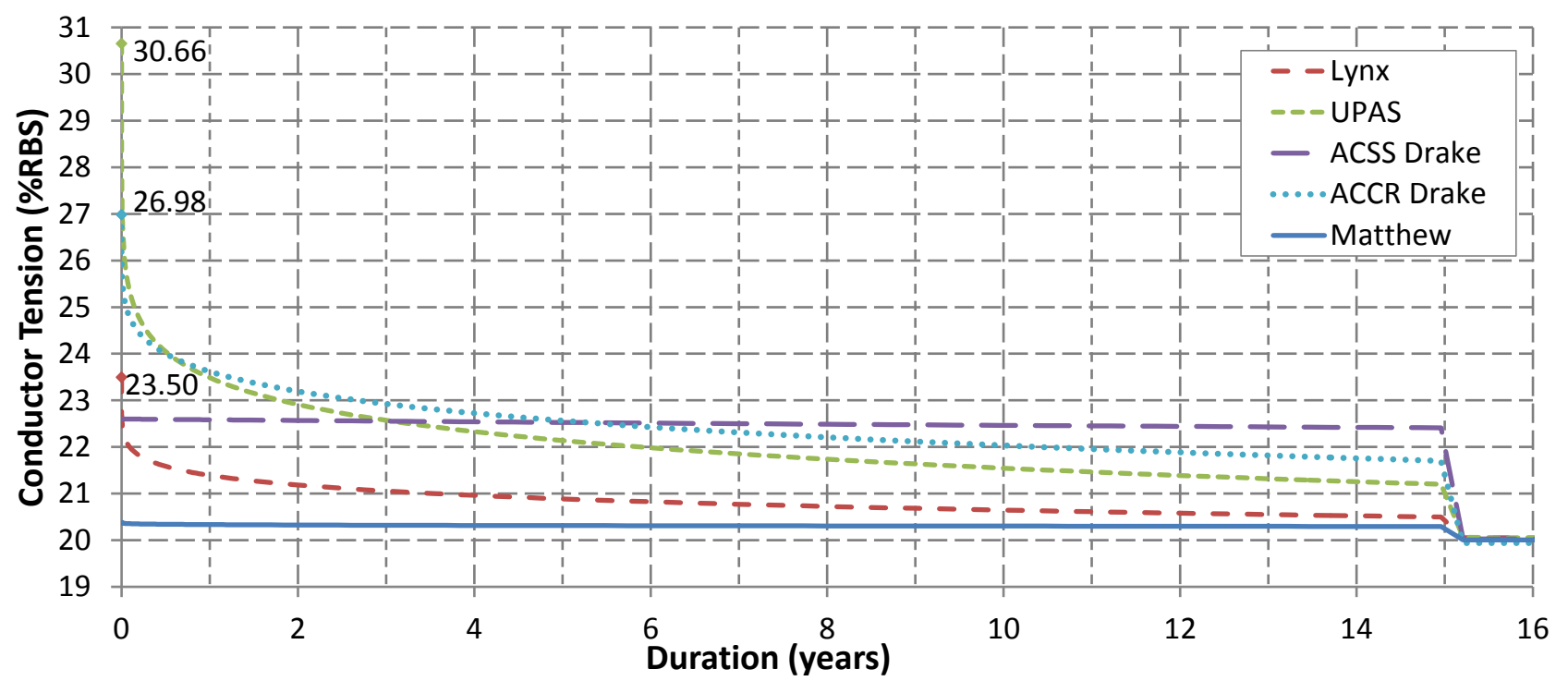

Fig. 7. Conductor everyday tension when over-tensioning is applied to mitigate the creep effect of Sc-3.

Lynx, Upas and ACCR Drake require large initial over-tensions to fully mitigate the creep effect which are exponentially reduced as everyday metallurgical deformation is developed. The tensions are reduced to the designed $20 \%$ RBS after the ice loading in $15^{\text {th }}$ year. The worse over-stressing is developed on the ACCR Drake due to its stronger core "constraining" the creep rate of aluminium.

When comparing the HTLS conductors, Matthew seems to be lightly overstressed with low impact of ice loading on its aluminium due to its large strength (and low ice loading). Matthew and ACSS Drake conductors have similar performance with almost constant over-stresses during the pre-ice duration. The over-stresses are expected to be more severe for creep mitigation of higher ice loading designs. It is also important to note that the aluminium everyday tension of all HTLS conductors is expected to be lower (due to their different force distribution) when compared to the tensions seen on Lynx and Upas. Thus HTLS conductors are expected to have better vibration damping performance. Finally Upas and ACCR Drake could critically overstress the OHL structure when ice loadings occur in the first couple of years after their installation.

\subsection{Combined Ice Loading and Emergency Thermal Operating Conditions}

Every OHL experiences ice loading based on its environmental conditions while combinations of operating and ambient weather conditions could result in elevated temperature ageing of the conductor at emergency loading [29]. This results in various scenarios of sequential ice loading and elevated thermal operating events during the conductor's life particularly for AAACs and ACSRs, since HTLS conductors maintain their integrity at the temperatures usually implemented [30]. The impact of the real-life conditions is examined for Lynx and Upas using the six scenarios presented in Table 5 and assuming one emergency OHL loading per year for the 30-year conductor life. The calculated results for each scenario are illustrated in Table 6 with the OTs identified in Section 4. 
Lynx is not affected by the elevated temperature as derived from the comparison of Sc-7, Sc-8, Sc-9 with Sc-10, Sc-11, Sc-12 which is in agreement with [18]. There is, however, a small change in sag due to the timing of occurrence of the ice loading, which will increase under higher ice loadings. Upas performance (Table 6) is affected by both the sequence and duration of the critical events. In particular, the emergency loading duration increase from 3 hours/year to 12 hours/year develops a $26 \mathrm{~cm}$ sag increase (Sc-7 vs Sc-10). Retaining the emergency loading to 3 hours/year and changing the ice loading occurrence from the $1^{\text {st }}$ to the $15^{\text {th }}$ year (Sc-7 vs Sc-8) the sag appears to increase by $18 \mathrm{~cm}$. Therefore, it can be seen that the time of occurrence of ice loading throughout the conductor's life has a significant impact (when compared to emergency loading impact) on sag and it cannot be neglected particularly for increased ice loading designs. The worse scenario is when the ice loading occurs at the $30^{\text {th }}$ year with an approximate $27 \mathrm{~cm}$ increase in sag when compared to the scenarios of ice loading event at the first year of installation (Sc-7 vs Sc-9). This study clearly indicates that for AAACs the extreme events should be considered in a sequential manner with the worse creep scenario being different from the one suggested in the current literature (i.e., Sc-7 or Sc-10) [15].

Table 5 Ice Loading \& Thermal Loading Scenario Data

\begin{tabular}{c|ccc|ccc}
\hline Scenarios & Sc-7 & Sc-8 & Sc-9 & Sc-10 & Sc-11 & Sc-12 \\
\hline Time of ice loading event $(\mathrm{y})$ & 1 & 15 & 30 & 1 & 15 & 30 \\
Total elevated temp. duration $(\mathrm{h})$ & 90 & 90 & 90 & 360 & 360 & 360 \\
\hline
\end{tabular}

Table 6 Creep Results for Base and combined ICE \& Thermal Loading Scenarios

\begin{tabular}{ccccccccc}
\hline \multicolumn{2}{l}{ Loading Scenarios } & Base & Sc-7 & Sc-8 & Sc-9 & Sc-10 & Sc-11 & Sc-12 \\
\hline \multirow{2}{*}{ Lynx } & $\operatorname{creep~}(\mu \varepsilon)$ & 518 & 536 & 571 & 592 & 536 & 571 & 592 \\
& $\operatorname{sag}(\mathrm{m})$ & 11.06 & 11.10 & 11.17 & 11.17 & 11.10 & 11.17 & 11.17 \\
\hline \multirow{2}{*}{ Upas } & $\operatorname{creep~}(\mu \varepsilon)$ & 1200 & 1305 & 1394 & 1439 & 1434 & 1515 & 1560 \\
& $\operatorname{sag}(\mathrm{m})$ & 10.90 & 11.10 & 11.28 & 11.37 & 11.36 & 11.51 & 11.60 \\
\hline
\end{tabular}

\section{Experimental Performance and Simulation Predictions for Matthew Conductor}

The accuracy of the methodology implemented here is evaluated with common conductors in [13]. In particular, the methodology is evaluated with a twin Rubus (AAAC) conductor on an L2-type lattice tower structure with a section of 4 spans installed in 1983 using an over-tension method at installation to mitigate for the creep. The average calculated forecasted sag error was $6.5 \mathrm{~cm}$ with maximum error being $20 \mathrm{~cm}$ for the $412 \mathrm{~m}$ span with sag of $12.12 \mathrm{~m}$ at the surveyed temperature [13]. The equivalent temperature shift was $26^{\circ} \mathrm{C}$ while IEC standards [31] suggest a lower value $\left(22^{\circ} \mathrm{C}\right)$ for temperature shift. Additional evaluations presented in [23] have similar level of accuracy. This section evaluates the accuracy of the methodology on HTLS conductors (as at that time of [13] no experimental data were available). Thus, Matthew experimental data as in [30] is now used, based on a $294.42 \mathrm{~m}$ span with a tangential installation tension of $33 \mathrm{kN}$ at $23^{\circ} \mathrm{C}$. Considering the weight span of $3.2 \mathrm{kN}$ then a $32.8445 \mathrm{kN}$ 
horizontal tension is applied. Matthew was heated up using a $2500 \mathrm{~A}, 600 \mathrm{~V}$ rms current transformer with a $0-11 \mathrm{kV}$ voltage regulator [30]. The temperature and tension measurements recorded for 4 months are illustrated in Fig. 8 along with the calculated predicted values (blue line) using the methodology in [13]. The predicted values are obtained using an EDOT of $23^{\circ} \mathrm{C}$ for the 4-month duration considering compressive forces on the conductor.

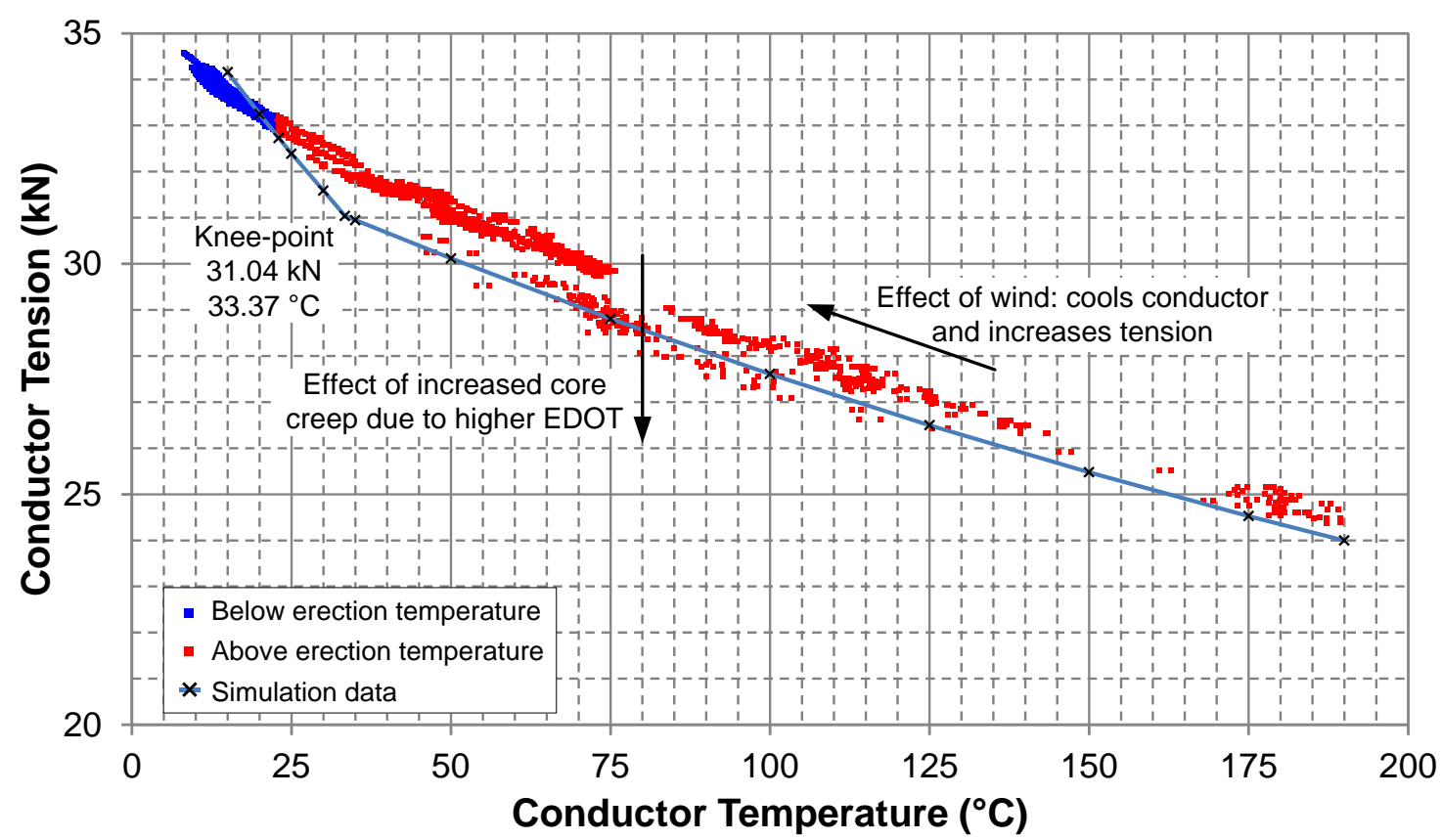

Fig. 8. Experimental and simulated conductor temperature and tension data.

The calculated predictions (Fig. 8) are quite accurate particularly at the high temperature range. The experimental data also indicate that there is a group of lower measured tensions at the mid-range temperatures. This is not due to wind effect since wind increases the conductor tension and thus higher tensions should be recorded [32]. Instead, this is the result of the increased creep-rate introduced on the conductor core due to higher EDOT (as discussed in previous sections) particularly after its extended thermal operation at $180^{\circ} \mathrm{C}$ during the test. The KPT can be distinguished on the predicted curve in Fig. 8 since calculations consider zero friction between the core and aluminium (i.e., ideal scenario). However, the experimental data do not indicate an exact KPT.

\section{Conclusions}

The methodology implemented predicted Matthew performance of the experiment performed in [30]. Using this methodology, it has been found that the pre-tensioning is not as effective as over-tensioning on the AAACs and ACSRs as it can practically remove only 40\%-50\% of the total long-term creep. The creep mitigation for these conductors by pre-tensioning can be estimated using the empirical equation (1). However, pre-tensioning can practically remove the long-term creep of ACSS and ACCR conductors without any over-stressing duration after installation. 
An important factor affecting conductor creep and sag is found to be the EDOT implemented in the design. The most conservative scenario for the AAAC and ACSR is to consider a low EDOT as more sag is produced and therefore the current practice (for $\mathrm{UK}$ ) of $5^{\circ} \mathrm{C}-15^{\circ} \mathrm{C}$ is appropriate. However, this practice cannot be used for the Gap-type conductor as the higher EDOT is the most conservative scenario. Consequently, to maintain Matthew's electrical performance, creep should be evaluated using an estimated maximum EDOT, which in most of the cases should be at least $20^{\circ} \mathrm{C}$ above the everyday temperature due to electrical loading. All other examined HTLS conductor technologies are found to be immune to EDOT variations.

When extreme events are considered in the OHL design with common conductor technologies, it is very important to account for the estimated duration of the expected conductor ice loading as this has an accountable effect on the creep which could be equivalent to or more severe than the elevated temperature operation effect on creep. Furthermore, the sequence of extreme events also affects the total creep produced with the larger values developed when ice loading occurs after elevated temperature operations. A realistic conservative scenario is to consider the first ice loading at conductor mid-life instead of at installation.

Mitigating the additional creep due to ice loading through over-tensioning could result in prolonged periods of conductor and structure over-stressing particularly in areas of infrequent and heavy ice events and when soft aluminium or Gap-type HTLS conductors are implemented. Thus, a combination of pretensioning with over-stressing should be considered.

The sag performance of HTLS conductors is technology dependent since different technologies and installation methods are implemented and cannot be expected to have similar (core and aluminium) creep behaviour as common conductor types. It should be noted that a $20 \mathrm{~cm}$ increase of sag due to creep for HTLS conductors could result in a considerable reduction of power capacity due to low thermal expansion of their core. Thus, core creep should not be neglected as within current practice, and consequently more advanced methods for both creep calculation and its improved mitigation, as suggested here, should be implemented.

\section{References}

[1] J. C. Roughan and D. Hearnshaw, "The development of a high performance vibration damper for alloy conductors," in International Conference on Overhead Line Design and Construction: Theory and Practice, 1988, pp. 60-64.

[2] F. R. Thrash, Jr., "ACSS/TW-An improved high temperature conductor for upgrading existing lines or new construction," in IEEE Power Engineering Society Summer Meeting, 2001, pp. 182-185. 
[3] S. Sakabe, N. Mori, K. Sato, Y. Miyake, and A. Tanaka, "Development of Extremely-Low-Sag Invar Reinforced ACSR (XTACIR)," IEEE Transactions on Power apparatus and systems, vol. PAS-100, pp. 1505-1511, 1981.

[4] J-Power Systems Corp.,Tokyo, Japan: "Gap type thermal-resistant aluminum alloy conductor steel reinforced", (Accessed on: 2012, Apr.) [Online] Available:

http://www.jpowers.co.jp/english/product/pdf/gap c1.pdf

[5] D. J. Johnson, T. L. Anderson, and H. E. Deve, "A new generation of high performance conductors," in Power Engineering Society Summer Meeting, 2001, pp. 175-179 vol.1.

[6] A. Alawar, E. J. Bosze, and S. R. Nutt, "A composite core conductor for low sag at high temperatures," IEEE Transactions on Power Delivery, vol. 20, pp. 2193-2199, 2005.

[7] J. R. Harvey and R. E. Larson, "Use of Elevated-Temperature Creep Data in Sag-Tension Calculations," IEEE Transactions on Power Apparatus and Systems, vol. PAS-89, No 3, pp. 380-386, 1970.

[8] M. Iordanescu, J. Tarnowski, G. Ratel, and R. Desbiens, "General model for sag-tension calculation of composite conductors," in IEEE Power Tech Proceedings, Porto, 2001, p. 4 pp. vol.4.

[9] C. B. Rawlins, "Some effects of mill practice on the stress strain behavior of ACSR," IEEE Transactions on Power Delivery, vol. 14, pp. 602-629, 1999.

[10] T. Kavanagh and O. Armstrong, "An evaluation of High Temperature Low Sag conductors for uprating the $220 \mathrm{kV}$ transmission network in Ireland," in 45th International Universities Power Engineering Conference (UPEC), 2010, pp. 1-5.

[11] Brochure 244 "Conductors for the Uprating of Overhead Lines," CIGRE, 2004.

[12] I. Albizu, A. J. Mazon, and I. Zamora, "Flexible Strain-Tension Calculation Method for Gap-Type Overhead Conductors," IEEE Transactions on Power Delivery, vol. 24, pp. 1529 - 1537, 2009.

[13] K. Kopsidas, S. M. Rowland, and B. Boumecid, "A Holistic Method for Conductor Ampacity and Sag Computation on an OHL Structure," IEEE Transactions on Power Delivery, vol. 27, pp. 1047-1054, 2012.

[14] J. S. Barrett, S. Dutta, and O. Nigol, "A New Computer Model of ACSR Conductors," IEEE Transactions on Power Apparatus and Systems, vol. PAS-102, pp. 614-621, 1983.

[15] CIGRE WG 22-05: Electra $N^{\circ} 75$ "Permanent elongation of conductors. Predictor equation and evaluation methods," 1981, pp. 63-98.

[16] J. Bradbury, P. Dey, G. Orawski, and K. H. Pickup, "Long-term-creep assessment for overhead-line conductors," Proceedings of the Institution of Electrical Engineers, vol. 122, pp. 1146-1152, 1975.

[17] J. Bradbury, G. F. Kuska, and D. J. Tarr, "Sag and tension calculations for mountainous terrain," IEE Proceedings C: Generation, Transmission and Distribution, vol. 129, pp. 213-220, 1982.

[18] "IEEE Guide for Determining the Effects of High-Temperature Operation on Conductors, Connectors, and Accessories," IEEE Std. 1283-2004, pp. 1-28, 2005.

[19] United Kingdom: "Overhead Line Handbook - Linesmans Manual M1 for 132, 275, and 400kV overhead lines," National Technical Training Centre (C.E.G.B.), 1989.

[20] T. Cahill, "Development of A Low-Creep ACSR Conductor," Wire Journal, vol. 6, pp. 66-73, 1973.

[21] Overhead Electrical Conductors - Calculation Methods For Stranded Bare Conductors, IEC Standard 61597, 1995.

[22] CIGRE TF B2-11-04: CIGRE Brochure 273 "Overhead Conductor Safe Design Tension With Respect To Aeolian Vibrations," 2005.

[23] K. Kopsidas, "Modelling Thermal Rating of Arbitrary Overhead Line Systems," PhD Thesis, Electrical and Electronic Engineering, The University of Manchester, Manchester, UK, 2009.

[24] I. Albizu, A. J. Mazon, V. Valverde, and G. Buigues, "Aspects to take into account in the application of mechanical calculation to high-temperature low-sag conductors," IET Generation, Transmission \& Distribution, vol. 4, pp. 631-640, 2010.

[25] K. Kopsidas, "Assessing the power transfer performance of a lattice tower overhead line system," IET Generation, Transmission \& Distribution, vol. 7, pp. 90-100, 2013.

[26] K. Kopsidas and S. M. Rowland, "A Performance Analysis of Reconductoring an Overhead Line Structure," IEEE Transactions on Power Delivery, vol. 24, pp. 2248-2256, 2009.

[27] K. Kopsidas, Engineering and Physical Sciences Research Council (EPSRC) "A tool for evaluating overhead line performance under novel technology implementations," 2014.

[28] UK Met Office,UK: "UK climate anomaly maps relative to 1961-1990 average", (Accessed on: 2014, Apr.) [Online] Available: http://www.metoffice.gov.uk/public/weather/climateanomalies/\#?tab=climateAnomalies 
[29] D. O. Koval and R. Billinton, "Determination of Transmission Line Ampacities by Probability and Numerical Methods," IEEE Transactions on Power apparatus and systems, vol. PAS-89, pp. 1485-1492, 1970.

[30] M. Tunstall, N. Derbyshire, S. Hoffmann, and M. Pyke,United Kingdom: Technical Report TR(E)327 "Assessment of 620 $\mathrm{mm}^{2}$ 'Matthew' GZTACSR Gap Type Conductor for use on L2 Towers," National Grid, March 1999.

[31] "IEC 61597: Overhead Electrical Conductors - Calculation Methods for Stranded Bare Conductors," International Electrotechnical Commission, May 1995.

[32] M. T. Bedialauneta, E. Fernandez, I. Albizu, A. J. Mazon, and K. J. Sagastabeitia, "Factors that affect the sag-tension model of an overhead conductor," in IEEE PowerTech, Grenoble, 2013, pp. 1-6. 